\title{
Review on NSM CFRP Strengthened RC Concrete Beams in Shear
}

\author{
Majid M. A. Kadhim, ${ }^{1}$ Mohammed J. Altaee, ${ }^{2}$ Ali Hadi Adheem, ${ }^{3}$ Ali Chabuk, ${ }^{4}$ \\ and Nadhir Al-Ansari $\left.{ }^{5}\right)^{5}$ \\ ${ }^{1}$ College of Engineering, University of Babylon, Hilla, Iraq \\ ${ }^{2}$ Research Centre and Environmental Studies, University of Babylon, Hilla, Iraq \\ ${ }^{3}$ Kerbala Technical Institute, Al-Furat Al-Awsat Technical University, Kerbala 56001, Iraq \\ ${ }^{4}$ Department of Environment Engineering, College of Engineering, University of Babylon, Babylon 51001, Iraq \\ ${ }^{5}$ Department of Civil Environmental and Natural Resources Engineering, Lulea University of Technology, Lulea 97187, Sweden \\ Correspondence should be addressed to Nadhir Al-Ansari; nadhir.alansari@ltu.se
}

Received 18 August 2021; Revised 6 October 2021; Accepted 11 October 2021; Published 27 October 2021

Academic Editor: Tan-Trung Bui

Copyright (C) 2021 Majid M. A. Kadhim et al. This is an open access article distributed under the Creative Commons Attribution License, which permits unrestricted use, distribution, and reproduction in any medium, provided the original work is properly cited.

\begin{abstract}
The use of NSM FRP strengthening of concrete structures has become an attractive option to retrofit the existing structures against shear and flexure. This paper reviews only the utilization of NSM for shear in previous review articles. A database of tests of NSM strengthened beams in shear is presented to evaluate the existing design formulations of calculating the NSM contribution in shear. These formulations were in agreement with the experimental results in the database. Further research topics are also identified such as the shape of NSM FRP bars, combined effects of existing steel stirrups, and NSM FRP reinforcement and analytical formulations.
\end{abstract}

\section{Introduction}

Sudden failure because of low resistance to shear is something required to be avoided. Thus, one of the priorities of researchers is to find an appropriate strengthening technique that can be employed to enhance RC beams when they are deficiently reinforced in shear, when they fall under higher loads, or when the shear capacity of beam is below the flexural capacity due to flexural strengthening for example. Employment of composite materials in strengthening/retrofitting concrete elements is one of these techniques. Externally bonded (EB) Carbon Fiber Reinforced Polymer (CFRP) is one of the earlier systems used in strengthening concrete elements in the case of using composite materials [1-7]. However, recently, using near surface mounted (NSM) with CFRP becomes one of the most investigated techniques in flexural [8-14] and shear strengthening [15-21] (see Figure 1) because of its advantages over externally bonded EB-CFRP reinforcement $[18,22]$ :
(1) The previous experimental studies have demonstrated that the NSM strengthening technique can provide higher strengthening effectiveness compared to EBR due to higher bonded area-to-cross-sectional area of the CFRP element ratio. For this reason, the NSM technique is less prone to debonding failure.

(2) The amount of site installation work needed in the case of the NSM technique is less than that required in EBR technique.

(3) In the case of intending of use prestressed CFRP reinforcements, NSM bars can easily be used.

(4) The NSM strengthening technique reduces the probability of harm resulting from accidental impact, mechanical damage, vandalism, and fire because the NSM bars are protected by the concrete cover.

(5) The appearance of structural member is uninfluenced with using the NSM strengthening technique. 


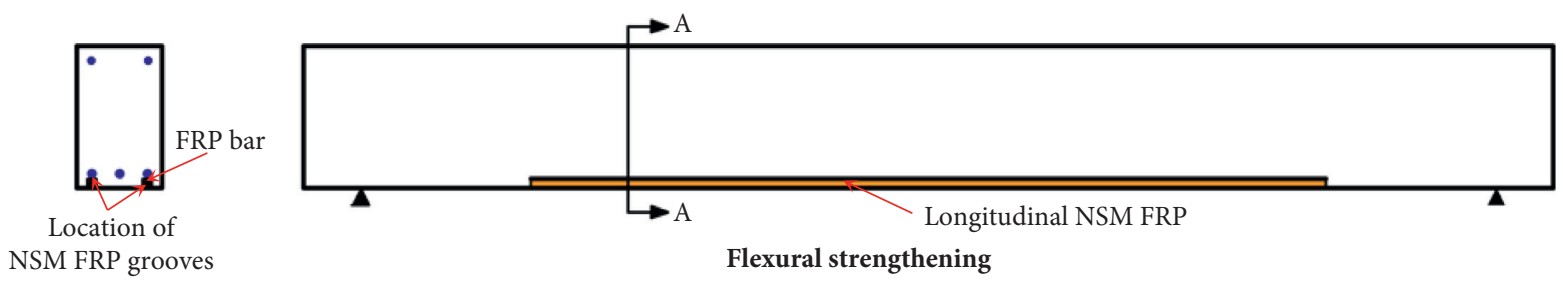

Section A-A

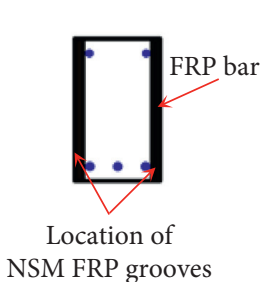

NSM FRP grooves

Section A-A

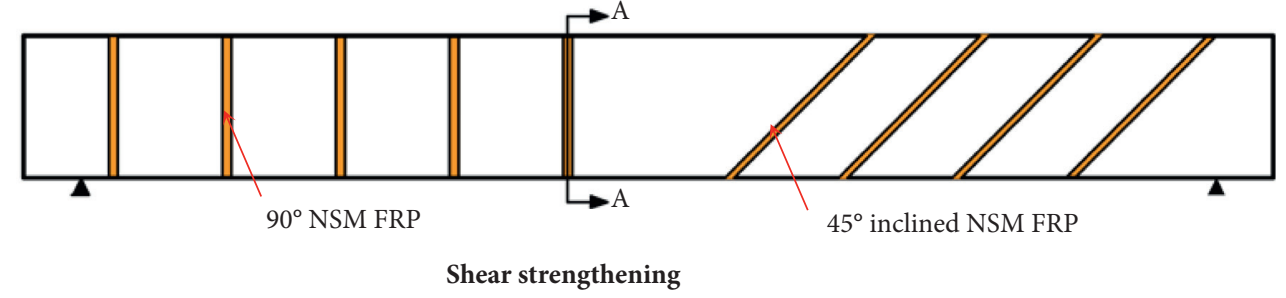

FIGURE 1: NSM FRP strengthening of beams in flexure and shear.
There is a growing body of literature that recognizes the importance of using the NSM strengthening technique because of the above listed advantages. Several review studies had been found in the literature [18,23-25]. However, to the best of the authors' knowledge, there is no one that has reviewed the research of shear contribution of NSM CFRP strengthening technique. This paper focuses on research studies that investigated the shear strengthening of RC beams with CFRP NSM technique. In addition, some aspects regarding the bond strength and the factors affecting the bond performance are also discussed. Finally, the design rules for prediction of the CFRP contribution of the NSM shear strengthening systems are evaluated.

\section{NSM Strengthening Technique}

In order to install the CFRP laminates using NSM system, grooves with a desired depth, width, inclination, and spacing were opened on the concrete cover by using saw-cutting [16, 26-28] or diamond cutter [29]. These grooves were then cleaned by compressed air [16, 26-29] and compressed water in some cases [30]. Then, the grooves were filled with the adhesive material. Finally, the CFRP laminates were inserted into the slits of the beam, and the excess adhesive material was removed.

2.1. FRP Reinforcement. FRP bars can be produced in a variety of shapes. Two different cross-sectional shapes were used in the previous research studies that conducted the strengthening of RC beam in shear, which are round bars and thin narrow strips (simply referred as "strips" hereafter). The selection of the cross-sectional shape depends on many factors such as the depth of the concrete cover, the cost of a particular type of bar, and the availability of this type. For instance, strips need a thicker concrete cover for a specific cross-sectional area, but they have better performance compared with round bars of equivalent cross-sectional area due to maximizing bond surface and hence reduce the risk of debonding failures in beams strengthened with NSM FRP strips [11].

The surface texture of FRP bars reinforcement was also varied to improve bond properties. In some cases, these bars were coated with epoxy paste and then sprinkled with 0.2 / $0.3 \mathrm{~mm}$ of surface sanding materials [31]. In other cases, the surface of the round bars was spirally wounded with a fiber tow and coated with sand [26].

2.2. Groove Geometry. It mainly depends on the FRP cross section and bars surface treatment. The choice of groove dimensions can influence the bond performance, and hence, it can cause premature debonding failure. The rectangular, square, or round bars are commonly used.

The square and rectangular bars have several merits over round bars, such that they provide a uniform adhesive thickness in their vertical and parallel sides. Moreover, the ratio of surface to cross section area of square and rectangular bars is higher than that of round bars. This can minimize the bond stresses for the same tensile force in the FRP, which may split the groove filling cover. Another advantage of using rectangular bars is related to the simplicity of opening the grooves. The main disadvantage of rectangular bars is the need for a deeper groove to provide the same reinforcement area $[18,32]$.

Several studies [33-36] showed that FRP rectangular bars, which have a large height-to-thickness ratio, are superior to NSM FRP bars of other shapes. This is due to a larger embedment depth and a higher perimeter/crosssectional area ratio than those FRP bars of other shapes, which consequently leads to a higher utilization capacity of FRP. The deeper FRP in the web provided higher shear strengthening, and the inclined FRP gave a more ductile behavior after peak load for the beams that were shear strengthened with NSM [37-39]. 
2.3. Groove Filler. The role of groove filler adhesive is to transfer the stresses between the FRP reinforcement and concrete. Two types of adhesive can be epoxy or cement based. The most relevant mechanical properties of groove filler are tensile and shear strengths. The tensile strength is especially important in case of round bars, which induce high circumferential tensile stresses in the epoxy [40]. The shear strength is especially important when the bond is controlled by cohesive shear failure of the epoxy. The cement based adhesive has some advantages vs. epoxy as follows: it is cheaper, presents reduced hazard to workers and environment, allows bonding to wet surfaces, has a better behavior at elevated temperatures, and is compatible with the concrete substrate. The main disadvantage is the low tensile strength compared to epoxy, and during hardening of the mortar, adequate wetting should be assured. Bond and flexural tests identified some limitations of cement mortar as grove filler [41]. The performance of the specimens with epoxy-filled grooves was almost similar and provided higher pull-out loads compared to the specimens with cement mortar adhesives [42]. The cementitious matrix with NSM strengthening system has generally improved the deformational characteristics of the strengthened specimens [39]. The NSM CFRP bar repair resulted in only a slight increase in stiffness and a slight decrease in strength due to the debonding of the vertical FRP in the web at the epoxy/mortar interface [43].

\section{Bond Behavior}

A key issue of the structural performance of the NSM technique is the bond behavior as for the EBR one, since the debonding of the FRP reinforcement can be a very common failure mode. Failure modes of the beams strengthened by the NSM technique were not brittle as those observed in the beams strengthened by the EBR technique [29].

Direct pull-out tests (DPT) including single or doublelap shear tests and beam pull-out tests (BPT) are commonly used to investigate the bond between NSM CFRP and concrete [18], which are described in more details elsewhere [24]. The above test methods have been used to investigate a wide range of parameters affecting the bond mechanism including: FRP fiber type and external surface [32, 33, 44-50], FRP axial stiffness [44, 47-53], FRP cross section geometry $[32,33,46,49,51,54-58]$, groove surface $[44,47,59,60]$, groove's geometry $[48,50,51,54,58,61,62]$, concrete strength $[33,45,46,50,52]$, and adhesive material type and bonded length $[32,45,46,52,53,57,63]$.

Different types of failure have been recorded in pull-out tests. However, in some cases, the authors of experimental works analysis tend to report more than one failure mode for the same specimen. Either this was a combination of several failure mechanisms or two failures may occur in sequence. It is thought by others [18] that any specimen should have one governing failure model and reporting more than one failure mode for a specific specimen may be caused by: (a) the occurrence of a sudden failure during the tests, hiding the possibility of observing the real failure mode, (b) in the case of BPT specimens, the test configuration itself could lead to erroneous identification of failure modes (the BPT are performed with test region (face where the FRP is applied) downwards, being more difficult to observe the development of the failure mechanism).

In this section, the locations of main failure modes that occurred in bond between NSM FRP-concrete substrate are summarized, as follows (see Figure 2).

3.1. Failure in FRP Material (FRP Rupture). It is simpler than other failure modes to recognize, and it occurs in NSM specimens with adequate bond length [32, 45, 64].

3.2. Failure at Interface FRP/Adhesive. This failure occurred when a clean FRP bar/strip without adhesive attached detached from adhesive layer. In fact, mechanical interlock between FRP and the surrounding adhesive, in addition to chemical adhesion and friction between FRP and adhesive, is responsible to have an efficient bond. This kind of failure is observed in NSM specimens with inadequate bonded length or bad FRP surface cleaning, and some cases may occur as a result of low tensile strength of the used adhesive $[25,32,65-67]$.

3.3. Cohesive Failure. This kind of failure occurs mainly as a result of the normal stresses developing together with longitudinal stresses during the test. When the normal stress reaches adhesive tensile strength, the cohesive failure then happens. The low tensile strength of adhesive material and the small NSM groove depth are of the common reasons that cause this failure $[25,40,67,68]$.

3.4. Failure at Interface Adhesive/Concrete. The failure between adhesive and concrete substrate is similar to that occurring between FRP bar and adhesive, and the reason of this failure may also be caused by the low tensile strength of adhesive material and inadequate bonded lengths $[40,41,45,50,64,69,70]$.

3.5. Concrete Fracture. The failure in concrete substrate is mainly caused by the low strength of concrete, so the failure is shifted to the weakest material in joints. This type of failure is commonly observed when adequate bonded lengths and the grooves geometry are well designed [32, 58, 64].

In addition, when NSM FRP strengthening technique used in flexure a side-groove may be the choice to improve the bond strength, in this case, the system can be called (side NSM) SNSM FRP strengthening technique. Several studies showed that the SNSM FRP technique can prove the same contribution when compared to the one used in the bottom of beams [71]. It also showed that SNSM can overcome the issue of concrete fracture since a wider area of concrete can prevent such king of failure.

It seems that the bond between NSM FRP reinforcement and concrete substrate is well covered. However, as an accurate method is needed to define and describe the failure modes observed, in addition, the prediction of pull-out strength of NSM FRP strips/rods, which are bonded to 


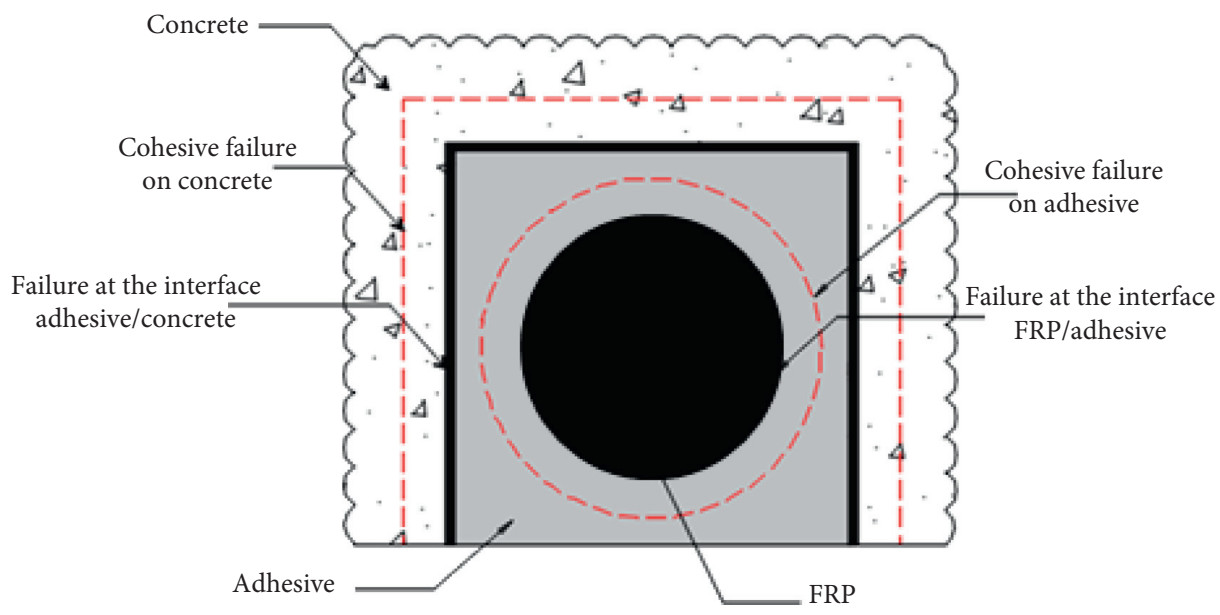

FIgURe 2: Possible failure modes associated with debonding mechanism [18].

concrete block, was investigated using fuzzy logic approach [72]. The results of the proposed model showed good accuracy against the experimental data and outperform the published models. For this reason, this kind of approach can also be utilized to propose methods of determining contribution of NSM FRP technique in flexure or shear as will be discussed later $[72,73]$.

\section{Factors Affecting NSM Strengthening}

The reported research studies that carried out the behavior of NSM CFRP strengthened RC beams in shear have investigated many parameters that can change the contribution of the NSM CFRP strengthening system in different levels. In the following sections, these parameters are listed and discussed.

4.1. Concrete Strength. The compressive strength of concrete was investigated in $[16,29,74,75]$ in three different series of experimental tests. The values of compressive strength were 18.6, 39.7, and 59.4 MPa at the age of beam tests. In each compressive strength of concrete, different NSM CFRP laminate inclinations $\left(45^{\circ}, 60^{\circ}\right.$, and $\left.90^{\circ}\right)$, levels of CFRP percentage $(0.06 \%, 0.09 \%-0.1 \%$, and $0.13 \%-0.16 \%)$ and levels of steel stirrups percentage $(0.1 \%, 0.16 \%$, and $0.17 \%)$ were investigated. The experimental results demonstrated that the higher the concrete compressive strength, the higher the NSM CFRP effectiveness. This is related to the fact that the effective bond length is decreased with the higher concrete strength due to the decreasing of the fracture failure of concrete in the groove surface for the RC beams made by higher concrete strength class. Because of that, the contribution of the NSM CFRP laminates for shear resistance of beams is increased with the higher tensile strength of the concrete. It was also found that the NSM CFRP technique is still effective in beams produced by the lowest structural compressive strength of concrete.

4.2. Existing Steel Stirrups. The ratio of the presence tension steel reinforcement was found to be very effective when NSM FRP strengthening technique was applied in flexure
[76-78]. In a similar way, the presence of steel stirrups has also a clear effect on the contribution of NSM FRP strengthening technique when it is used in shear. Several studies have tried to investigate the effectiveness of NSM FRP strengthening technique with different percentages of steel shear reinforcements [29, 30, 74, 75, 79-81]. Lorenzis and Nanni [79] tested series of RC beams with absence and with steel stirrups. It is not possible to make a comparison between the tested beams because of the differences in the percentage of CFRP applied for the beams. However, it is only possible to conclude that the contribution of the NSM CFRP strengthening technique is still significant in the presence of steel stirrups. Another set of experimental studies $[29,74,75,80]$ revealed that the effectiveness of NSM CFRP rods is more pronounced in the beams with the lower internal steel stirrups ratio. This conclusion was made by investigating different percentages of steel stirrups (0.1, 0.16-0.17). In contrast, Mofidi et al. [30] claimed that the internal steel stirrups and strengthening NSM CFRP did not diminish each other's influence. Furthermore, a database of more than 69 RC beams strengthened with NSM CFRP laminates or rods was analyzed by the same authors [30]. It was found that the shear contribution of the NSM CFRP bars or laminates slightly increased with the increase in the internal shear steel reinforcement. Based on the aforementioned discussions, this discipline may need more research.

The effectiveness of NSM CFRP bars in improving the shear capacity of concrete beams with corroded steel stirrups was also studied [82]. Two corrosion levels were investigated comprising $8 \%$ and $15 \%$. It was found that the contribution of the NSM CFRP strengthening technique was more pronounced with the lower stirrups corrosion of $8 \%$. This is thought to be caused by the heavily corroded steel stirrups that minimized the friction resistance at the steel stirrupsconcrete interface. This caused premature separation of the lateral concrete cover after onset of diagonal shear cracks. This process may reduce the effectiveness of NSM CFRP strengthening in shear.

The steel fibers would be used also to increase the shear resistance of concrete substrates. Therefore, NSM CFRP efficiency can be improved by using the steel fibers in 
concrete mix due to its ability to control the shear failure [83-86].

4.3. Shape of NSM CFRP Reinforcement. In the case of using NSM CFRP strengthening technique in enhancing RC beams in flexural capacity, it was found that using strips instead of round bars (having the same cross-sectional area) can improve the performance of NSM technique [11]. This was believed to be caused by maximizing the bond area and, therefore, reducing the debonding risk. Even with shear strengthening, the above conclusion can also be drawn [81]. However, this mechanism seems to be not identical with the test results reported by Rizzo and Lorenzis [26] who tested a series of RC concrete beams strengthened using NSM CFRP strengthening technique in shear. This finding cannot be normalized for many reasons, among which are the following:

(i) The cross-sectional areas of the round bar and the strip are different $\left(50 \mathrm{~mm}^{2}\right.$ for the round bars and $32 \mathrm{~mm}^{2}$ for the strips).

(ii) In the test reported in this section, all samples failed in concrete cover splitting in the region of the internal steel stirrups regardless of the strengthening configurations. Thus, the efficiency of CFRP strengthening cannot be obtained from this sample design.

More studies are needed to make the right selection of the NSM reinforcement shape.

4.4. Length of NSM Reinforcement. The length of FRP bars also plays an important role in controlling the contribution of this kind of strengthening technique [87]. Due to the limited depth of RC beams, the length of CFRP reinforcements was equal to the beam depth for the rectangular cross section beams in the most experimental tests [17, 31, 88]. However, using NSM strips with the length of $1 / 2 \mathrm{D}$ or $2 / 3 \mathrm{D}$ (D is the depth of beam) caused a noticeable improvement in the ultimate load of beam compared to using the length of NSM strips covering the full depth of beam [89]. The ultimate load of beams strengthened with full-length NSM strip was capable of sustaining a $144 \%$ higher load than that having length of NSM strips $1 / 2 \mathrm{D}$. The propagation crack passed directly into the end of the NSM strip in beams strengthened with NSM strips having the length of $1 / 2 \mathrm{D}$ or $2 / 3 \mathrm{D}$ causing a high stress concentration at the end, which accelerates the debonding. This did not occur in the case of using NSM CFRP strips with length equal to beam depth since the length contributes more of a bonding area than the other lengths.

In the case of T-beam strengthened with CFRP bars using NSM strengthening technique, extending the CFRP bars into the flange of the beam can increase the contribution of the CFRP bars $[79,90]$ as shown in Figure 3(a), whereas generally the CFRP bars or strips are installed on the side of the beam web as shown in Figure 3(b). This was partly caused by the extra CFRP material added to the beam. For

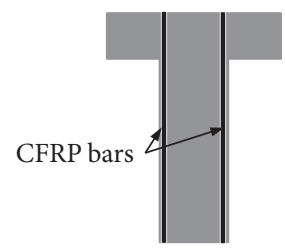

(a)

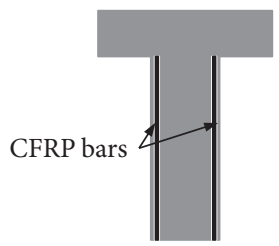

(b)
FIgURE 3: CFRP bars arrangements. (a) Anchorage in the flange. (b) On the side of the beam web.

example, $33 \%$ more material as reported by Lorenzis and Nanni [79] caused $45.5 \%$ increasing in the beam capacity. Another reason is the extra length of CFRP bars that caused an increase in the bonded length, and hence, it maximized the failure load.

These findings were also confirmed by other researchers $[17,28,88]$ who investigated the influence of CFRP length on rectangular cross section beams. This was conducted by increasing the beam depth to examine its impact on the CFRP contribution.

4.5. Mechanical Properties of Groove Filling's Material. The influence of mechanical properties of groove filling material has widely been investigated $[36,47]$ to find its effect on the bond strength. It has been found that the change in the properties of groove filling material has a significant effect on the bond strength and lesser extends on the failure mode. In particular, when a stiffer adhesive material was used as a groove filling material, the bond strength was increased [36, 47]. However, these results are not in agreement with those obtained by Rizzo and Lorenzis [26] who studied the shear contribution of the NSM strengthening technique. They found that, by using an epoxy having lower elastic modulus as a groove filling material, the NSM CFRP contribution to the shear capacity was more than twice in comparison with that used an epoxy with higher elastic modulus. It was believed that the epoxy with lower modulus of elasticity leads to more ductile bond-slip response, which can then delay the onset of debonding. This contrast may be related to the points listed in Section 4.3. This factor needs more research to be clearer.

4.6. Percentage of NSM Reinforcement. Generally, the increase in the percentage of the CFRP leads to an increase in the shear resistance of the strengthened beams $[16,28,29,74,75,81,88,91]$. It can be seen in Figure 4 that the increase of the beam's capacity as a result of increasing the percentage of the NSM CFRP reinforcement $\left(\rho_{f}\right)-$ which can be calculated as in equation (1) -is sensitive to the value of concrete compressive strength [75]. In other words, the efficiency of NSM strengthening technique for the shear strengthening is maximized with the higher concrete strength. This is related to the fact that, in the case of lower concrete strength, the failure mode in the strengthened beams is concrete fracture, in which the concrete adhered to the detached laminates, while in the case of higher concrete 


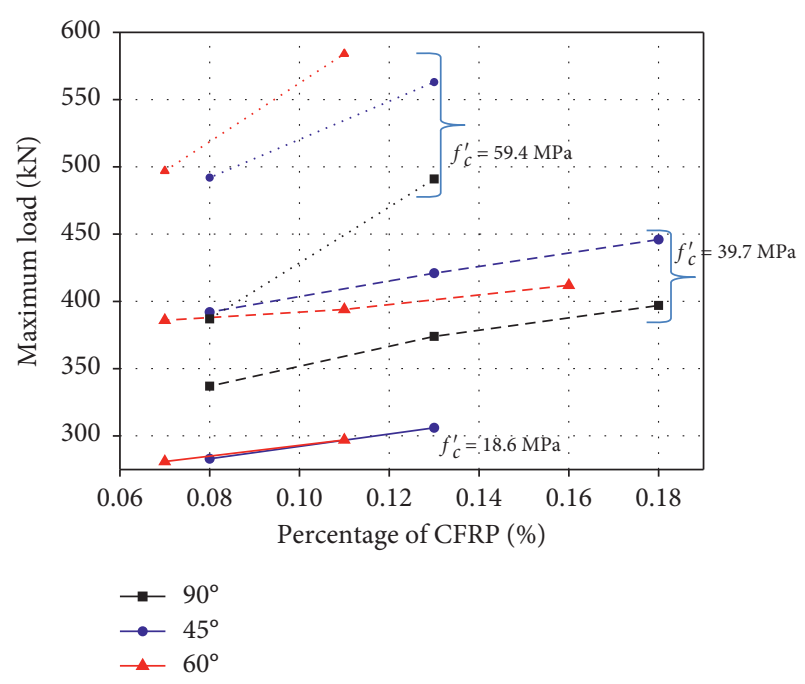

FIGURE 4: CFRP contribution against percentage of CFRP reinforcement with various concrete compressive strength and NSM CFRP inclination [75].

strength, the failure mode is either the sliding of CFRP laminate (between the CFRP and the epoxy) or the rupture of the CFRP [75]. Thus, it is expected for the lower concrete strength that the increase in the percentage of CFRP does not have a significant change in the efficacy of NSM technique for the shear resistance.

$$
\rho_{f}=\frac{2 \times A_{f}}{b_{w} \times S_{f} \times \sin \theta_{f}} \times 100,
$$

where $A_{f}$ is the area of the CFRP reinforcement (strip or bar) cross section, $b_{w}$ is the width of beam web, $S_{f}$ is spacing of the CFRP reinforcement, and $\theta_{f}$ is the orientation angle of the CFRP reinforcement with respect to the beam axis.

These findings seem to be incompatible with those presented in Rizzo and Lorenzis [26], where the increase in the percentage of the CFRP caused a decrease in the shear capacity of the beam. It was thought that increasing the percentage of CFRP accelerated the formation of debonding between CFRP bar and adhered layer.

4.7. Inclination of NSM Reinforcement. It is well known that inclined steel stirrups are more effective in shear resistance than the vertical stirrups because of diagonal cracking pattern of shear failure in RC beams. This phenomenon is identical with that found in the case of NSM CFRP strengthening technique $[27,29,74,75,79,81,88,90,92]$ (see Figure 4). This is partly caused by the orientation of the shear cracks that tend to be almost orthogonal to the inclined CFRP reinforcement [75]. In addition, the inclined CFRP reinforcement has better total resisting bond length than the vertical CFRP reinforcement because the inclined laminates are longer than vertical laminates. Thus, it is expected to delay the debonding failure and hence have higher shear resistance. It can be seen in Figure 4 that the orientation of CFRP reinforcement at $45^{\circ}$ was the most effective in some cases, while the orientation of CFRP laminate at $60^{\circ}$ was the most effective than other orientations in the other cases [75]. Thus, more investigations about this point are needed.

4.8. Distance between Existing Steel Stirrups and NSM Reinforcement. The relative position between internal steel stirrups and applied CFRP reinforcement has a specific contribution on the effectiveness of CFRP shear strengthening configuration [27]. It was found that when the applied NSM reinforcement intercepted the existing steel stirrups, this may cause a debonding for the NSM bars/strips. This reflects the importance of applying the CFRP NSM reinforcement with a homogenous distance with the existing steel stirrups. Further studies are important here to find the minimum distance (between laminates and existing steel stirrups), in which the influence of this factor can be neglected.

4.9. End Conditions of FRP Bars. This kind of treatment is very important when the governing failure mode is the debonding of FRP bars or concrete cover separation. In these cases, this kind of treatment can play an important role to avoid these kinds of failures. One of the effective methods to improve end conditions of FRP bars is bending the ends of FRP bars with angles ranging between $45^{\circ}$ and $90^{\circ}$ as reported by others [93]. As a result, it was found that this kind of end condition can increase the load carrying capacity of $\mathrm{RC}$ beams in flexure by $201 \%$ and $185 \%$ compared to the reference beam. Based on that, bent ends can be also investigated in the case of shear strengthening to eliminate the problem of premature debonding in the case of shallow beams for instance.

4.10. Concrete Cover Depth. The effect of the side cover depth was investigated by [89]. Generally, it was found that, by increasing side concrete cover depth, the side concrete cover separation can be delayed or even prevented [89, 94, 95]. However, increasing the side cover could have a negative effect on the flexural response of beams since it may limit the space provided to position the longitudinal reinforcement. In addition, in many cases, NSM FRP strengthening technique is used for repairing or strengthening existing structures; thus, increasing the side concrete cover may not be an option to improve the entire contribution of this technique.

\section{Failure Modes}

In the cases of evaluating the shear strengthening contribution, the RC beams were designed to assure shear failure mode. The failure modes occurring in the case of using CFRP NSM in shear strengthening are as follows:

(a) The first failure mode happened when the normal or low strength concrete is used. In this failure mode, the laminates/bars failed by debonding (see Figure 5). However, along the bond length, a thin layer of concrete adhered to the laminate/bar; 

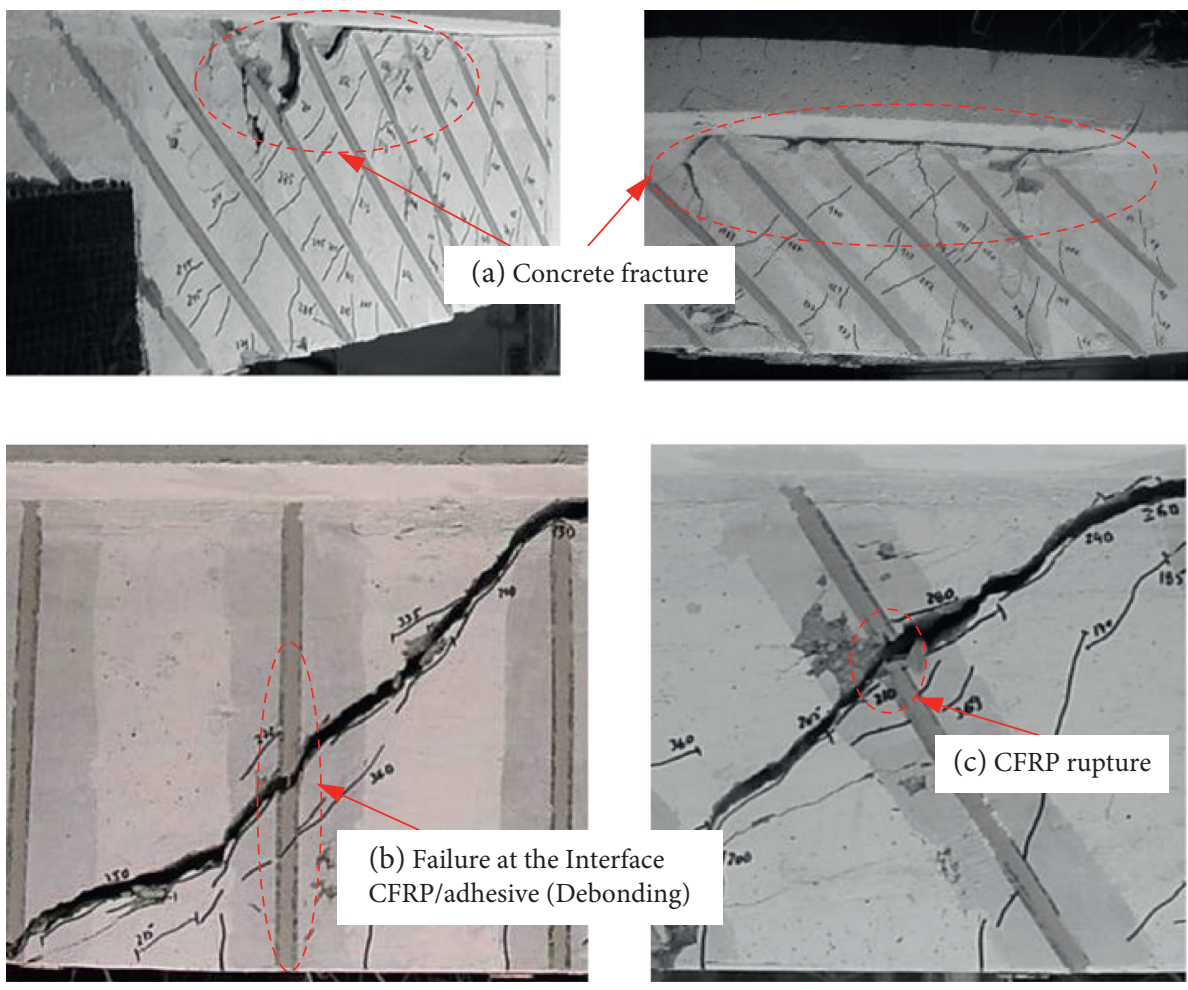

FIgURE 5: Failure modes ( $a, b$, and c) of the RC beams shear strengthened with NSM CFP laminates [75].

hence, this can be classified as a concrete fracture. In the case of high percentage of CFRP used, a concrete layer with a group of CFRP reinforcements detaches to create a "concrete lateral wall" that has separated from the overall volume of concrete $[75,88]$. In this bullet-point, two failure modes are presented, which are failure at interface between adhesive and concrete (debonding) and cohesion failure on concrete (concrete fracture), because, in many cases, these failure modes are difficult to be experimentally separated.

(b) The failure of interface between the NSM FRP reinforcement and the adhesive "debonding" shown in Figure 5 can be classified as the most common failure mode. This failure mode occurred when a normal to high concrete strength is used [75]. The interface CFRP/adhesive is the weakest point in the CFRP NSM strengthening technique. Thus, by using a high strength adhesive material, longer CFRP reinforcements, anchoring the CFRP in the flange of T-beam, etc., this weak point can be overcome.

(c) The rupture of CFRP can occur when a normal to high concrete strength is used as shown in Figure 5.

(d) In some cases, when the CFRP NSM reinforcement is applied to T-beams, shear splitting failure occurred along the web-flange interface region [90]. Extending CFRP NSM reinforcement can control this failure mode. (e) Regarding the beams tested without internal shear reinforcements, splitting of concrete cover of the flexural reinforcement occurred as a result of growing cracks along the flexural reinforcement. This was thought to be caused by designing the tested beams without steel stirrups, which are responsible for maintaining the dowel force and hence restraining the splitting cracks.

It should be noted that there is no cohesive failure on the adhesive observed in the experimental studies that conducted the shear contribution of CFRP NSM strengthening technique. This is because of the higher tensile strength of adhesive material compared to the concrete tensile strength in all tests.

\section{Analytical Formulations}

The prediction of the shear capacity of $\mathrm{RC}$ beams is a challenging task because shear mobilizes several complex resisting mechanisms such as (1) shear resistance assured by the uncracked concrete in the compression zone; (2) interface shear transfer by aggregate interlocking in the cracked concrete; and (3) the dowel action of the longitudinal reinforcement [96]. Several analytical formulations were proposed in order to predict the contribution of the NSM CFRP laminates for the shear capacity of RC beams $[74,75,79,97-108]$. Some of these models were only set to predict a certain failure mode such as Rizzo and Lorenzis 
TABle 1: Different methods to calculate the shear stresses by NSM FRP.

\begin{tabular}{|c|c|c|}
\hline Expression & Reference & Notation \\
\hline$V_{f}=2 \pi d_{b} \tau_{b} L_{\text {tot min }} \sin \theta_{f}$ & $\begin{array}{c}\text { Nanni, et al. } \\
{[98]}\end{array}$ & $\begin{array}{l}d_{b} \text { and } \tau_{b} \text { : diameter and average bond stress of the CFRP; } \theta_{f} \text { : } \\
\text { angle of CFRP bar to the beam longitudinal axis; and } L_{\text {tot min }} \text { : } \\
\text { effective bond length. }\end{array}$ \\
\hline $\begin{array}{l}V_{f}=h_{w}{ }_{\frac{A_{f v}}{s_{f}}} \varepsilon_{f e} E_{f}\left(\cot \alpha+\cot \theta_{f}\right) \sin \theta_{f} \\
\varepsilon_{f e}=3.76888 \times e^{\left(-0.116026 \theta_{f}+0.0010437 \theta_{f}^{2}\right)} \times \\
{\left[\left(E_{f} \times \rho_{f}+E_{s} \times \rho_{s w}\right) /\left(f_{c m}\right)^{2 / 3}\right]^{-0.460679 \times e^{\left(0.0351199 \theta_{f}-0.0003431 \theta_{f}^{2}\right)}}}\end{array}$ & $\begin{array}{l}\text { Dias and } \\
\text { Barros [75] }\end{array}$ & $\begin{array}{l}h_{w}: \text { web depth of the beam; } A_{f v}: \text { area of two CFRP bars; } s_{f} \text { : } \\
\text { spacing of the bars; } E_{f}: \text { elastic modulus of the CFRP; } \alpha: \\
\text { orientation of the shear failure crack; and } \varepsilon_{f e}: \text { effective strain. }\end{array}$ \\
\hline
\end{tabular}

[107]. Two main analytical formulations are detailed in the later sections. From these analytical formulations, the FRP contribution can be calculated. However, the nominal shear strength of RC beams strengthened with NSM FRP technique can be computed as suggested by Lorenzis and Nanni [79] using the equation by adding a third term to the basic equation provided by ACI code [109], as in

$$
V_{u}=\phi\left[\left(V_{c}+V_{s}\right)+\psi V_{f}\right]
$$

where $\phi$ is the strength reduction factor for shear strengthening of RC elements, which has a value of 0.85 as reported by ACI [109]. $\psi$ is an additional reduction factor for the case of externally bonded CFRP. The value of this reduction factor is 0.85 as recommended by ACI 440 committee [110]. The values of $V_{c}$ and $V_{s}$ are the contributions of concrete and steel stirrups, respectively, which may be computed according to standard concrete design codes. $V_{f}$ represents the contribution of NSM FRP reinforcement to shear. The main output is the value of NSM FRP contribution $\left(V_{f}\right)$ which can be calculated as per Table 1 .

\section{Evaluation of the Existing Formulations}

In the previous section, a brief review is presented for the formations proposed in the literature that aimed at predicting the contribution of NSM FRP laminates in shear. In order to evaluate these formulations, the results obtained from them compared with the experimental results extracted from previous experimental research studies are listed in Tables 2 to 6 . In these tables, $f_{f}^{1}$ and $f_{f}^{2}$ represent the values of shear contribution of the NSM FRP strengthening technique as predicted by Dias and Barros [75] and Nanni et al. [98] equations (equations 9 and 3), respectively.

The values of mean of $f_{f}^{1} / f_{f}^{\exp }$ and $f_{f}^{2} / f_{f}^{\exp }$ in Tables 2-6 have been calculated to evaluate these formations against the experiment's results. Since the mean values were 1.09 and 0.87 for the results using Dias and Barros [75] and Nanni et al. [98] formulations, respectively, the strength prediction using Dias and Barros [75] formula is closer than that obtained by using Nanni et al. [98] formula to the experimental strength. This may be attributed to the fact that the latter formula does not include the modulus of elasticity and effective strain of CFRP. However, these closed predictions do not mean that this formulation could capture the behavior in most cases. For instance, both formulations did not account for the effect of epoxy type into the contribution of NSM FRP technique as shown in Figure 6. It can be noticed from this figure that the use of a stiffer and stronger groove filling epoxy resulted in a lower FRP contribution to the shear capacity. The reason for this is related to the fact that the stiffer bond-slip response of the joints induced larger peak bond stresses and then accelerated the initiation of debonding cracks in the concrete [26].

In addition, it can be seen from Figure 7 that the predictions of Dias and Barros [75] for the contribution of NSM FRP strengthening technique in shear $\left(V_{f}^{1}\right)$ are less than the corresponding experimental values $\left(V_{f}^{\exp }\right)$ in most points. However, in others, the predictions of Dias and Barros [75] are not conservative since their predictions $\left(V_{f}^{1}\right)$ are more than the corresponding experimental values. Furthermore, considering the formulation suggested by Nanni et al. [98], it seems that although this formulation provides quite conservative predictions, their conservatism is relatively high in some points.

Regarding the effect of existing steel stirrups shown in Figure 8, it seems that the later formulation did not account for the percentage of existing steel reinforcement in their formulations. Although the predictions of Dias and Barros [75] include the influence of steel stirrups, their predictions are still overestimated compared to the corresponding experimental values. Thus, further modifications regarding this point may be needed.

Generally, the accuracy of the predictions of the theoretical formulations discussed in this section is accepted in many cases. However, further improvement is required to include the effect of some parameters such as epoxy properties, while further modifications are required to improve the predictions for some parameters such as the percentage of existing steel stirrups.

\section{Numerical Modelling}

It is well known that the numerical modelling is a powerful tool that is widely used in order to provide a comprehensive understanding to many phenomena in structural engineering applications. However, the number of numerical studies conducting the response of NSM CFRP strengthened concrete beams in shear is still limited. Some of these studies were only presented a simple numerical model without a deep discussion about the materials modelling and other numerical model characteristics [19]. Others tried to use these models to investigate more parameters [113-115]. Some of these parameters were already experimentally covered such as concrete compressive strength [113-115], 
TABLE 2: Comparison between experimental results [27] and analytical results.

\begin{tabular}{|c|c|c|c|c|c|c|c|c|c|c|}
\hline Symbols & $S_{f}(\mathrm{~mm})$ & $\theta^{\circ}$ & $a_{f}(\mathrm{~mm})$ & $b_{f}(\mathrm{~mm})$ & $E_{f}(\mathrm{GPa})$ & $V_{f}^{1}(\mathrm{kN})$ & $f_{f}^{2}(\mathrm{kN})$ & $f_{f}^{\exp }(\mathrm{kN})$ & $f_{f}^{1} / f_{f}^{\exp }$ & $f_{f}^{2} / f_{f}^{\exp }$ \\
\hline 2S-3LV-I & 267 & 90 & 1.4 & 10 & 166.6 & 21.6 & 20.4 & 22.2 & 0.97 & 0.91 \\
\hline $2 \mathrm{~S}-5 \mathrm{LV}-\mathrm{I}$ & 160 & 90 & 1.4 & 10 & 166.6 & 31.8 & 20.4 & 25.2 & 1.26 & 0.80 \\
\hline 2S-8LV-I & 100 & 90 & 1.4 & 10 & 166.6 & 41.7 & 40.8 & 48.9 & 0.85 & 0.83 \\
\hline 2S-3LI45-I & 367 & 45 & 1.4 & 10 & 166.6 & 43.4 & 14.4 & 29.4 & 1.47 & 0.48 \\
\hline 2S-5LI45-I & 220 & 45 & 1.4 & 10 & 166.6 & 47.3 & 28.8 & 41.4 & 1.14 & 0.69 \\
\hline 2S-8LI45-I & 138 & 45 & 1.4 & 10 & 166.6 & 63.5 & 28.8 & 40.2 & 1.57 & 0.71 \\
\hline 2S-3LI60-I & 325 & 60 & 1.4 & 10 & 166.6 & 28.0 & 17.6 & 35.4 & 0.79 & 0.50 \\
\hline 2S-5LI60-I & 195 & 60 & 1.4 & 10 & 166.6 & 37.4 & 22.3 & 46.2 & 0.80 & 0.48 \\
\hline 2S-7LI60-I & 139 & 60 & 1.4 & 10 & 166.6 & 50.8 & 35.3 & 54.6 & 0.93 & 0.64 \\
\hline 2S-7LV-II & 114 & 90 & 1.4 & 10 & 166.6 & 59.9 & 35.2 & 28.32 & 2.1 & 1.24 \\
\hline 2S-4LI45-II & 275 & 45 & 1.4 & 10 & 166.6 & 31.7 & 14.4 & 33.9 & 0.93 & 0.42 \\
\hline 2S-7LI45-II & 157 & 45 & 1.4 & 10 & 166.6 & 38.4 & 28.8 & 48.0 & 0.8 & 0.6 \\
\hline 2S-4LI60-II & 243 & 60 & 1.4 & 10 & 166.6 & 50.5 & 17.6 & 33.06 & 1.52 & 0.53 \\
\hline 2S-6LI60-II & 162 & 60 & 1.4 & 10 & 166.6 & 30.7 & 35.3 & 42.72 & 0.71 & 0.82 \\
\hline 4S-7LV-II & 114 & 90 & 1.4 & 10 & 166.6 & 38.2 & 35.2 & 6.9 & 5.53 & 5.10 \\
\hline 4S-4LI45-II & 275 & 45 & 1.4 & 10 & 166.6 & 31.7 & 14.4 & 26.04 & 1.21 & 0.55 \\
\hline 4S-7LI45-II & 157 & 45 & 1.4 & 10 & 166.6 & 38.4 & 28.8 & 31.56 & 1.21 & 0.91 \\
\hline 4S-4LI60-II & 243 & 60 & 1.4 & 10 & 166.6 & 50.5 & 17.6 & 25.08 & 2.013 & 0.70 \\
\hline 4S-6LI60-II & 162 & 60 & 1.4 & 10 & 166.6 & 30.7 & 35.3 & 35.1 & 0.87 & 1.00 \\
\hline 3S-5LI45-III & 275 & 45 & 1.4 & 10 & 174.3 & 38.2 & 39.9 & 66.1 & 0.57 & 0.60 \\
\hline 3S-5LI45F1-III & 275 & 45 & 1.4 & 10 & 174.3 & 93.6 & 39.9 & 85.75 & 1.09 & 0.46 \\
\hline 3S-5LI45F2-III & 275 & 45 & 1.4 & 10 & 174.3 & 93.6 & 39.9 & 65.35 & 1.43 & 0.61 \\
\hline 5S-5LI45-III & 275 & 45 & 1.4 & 10 & 174.3 & 93.6 & 39.9 & 74.9 & 1.24 & 0.53 \\
\hline 5S-5LI45F-III & 157 & 45 & 1.4 & 10 & 174.3 & 93.6 & 79.8 & 74.9 & 1.24 & 1.06 \\
\hline 3S-9LI45-III & 157 & 45 & 1.4 & 10 & 174.3 & 122.3 & 79.84 & 101.85 & 1.20 & 0.78 \\
\hline 5S-9LI45-III & 275 & 45 & 1.4 & 10 & 174.3 & 122.3 & 39.9 & 108.9 & 1.12 & 0.36 \\
\hline 3S-5LI60-III & 243 & 60 & 1.4 & 10 & 174.3 & 93.6 & 48.8 & 69 & 1.35 & 0.70 \\
\hline 5S-5LI60-III & 243 & 60 & 1.4 & 10 & 174.3 & 74.1 & 48.8 & 73.35 & 1.01 & 0.66 \\
\hline 5S-5LI60F-III & 243 & 60 & 1.4 & 10 & 174.3 & 74.1 & 48.8 & 72.55 & 1.02 & 0.67 \\
\hline 3S-8LI60-III & 162 & 60 & 1.4 & 10 & 174.3 & 74.1 & 75.7 & 112.3 & 0.65 & 0.67 \\
\hline 5S-8LI60-III & 162 & 60 & 1.4 & 10 & 174.3 & 91.8 & 75.7 & 122.45 & 0.74 & 0.61 \\
\hline 3S-6LV-III & 180 & 90 & 1.4 & 10 & 174.3 & 91.8 & 56.4 & 39.58 & 2.31 & 1.42 \\
\hline 3S-10LV-III & 114 & 90 & 1.4 & 10 & 174.3 & 40.3 & 71.3 & 83.25 & 0.48 & 0.85 \\
\hline
\end{tabular}

TABLE 3: Comparison between experimental results [111] and analytical results.

\begin{tabular}{lccccccccc}
\hline Symbols & $S_{f}(\mathrm{~mm})$ & $\theta^{\circ}$ & $\varnothing_{f}(\mathrm{~mm})$ & $E_{f}(\mathrm{GPa})$ & $f_{f}^{1}(\mathrm{kN})$ & $f_{f}^{2}(\mathrm{kN})$ & $f_{f}^{\exp }(\mathrm{kN})$ & $f_{f}^{1} / f_{f}^{\exp }$ & $f_{f}^{2} / f_{f}^{\exp }$ \\
\hline B2-FRP-V & 152 & 90 & 9.0 & 124 & 47.8 & 67.2 & 44.5 & 1.07 \\
B3-FRP-V & 305 & 90 & 9.0 & 124 & 30.9 & 67.2 & 31 & 0.99 \\
B4-FRP-V & 191 & 90 & 9.0 & 124 & 44.6 & 67.2 & 35.5 & 1.16 \\
\hline
\end{tabular}

TABLe 4: Comparison between experimental results [26] and analytical results.

\begin{tabular}{lccccccccccc}
\hline Symbols & $S_{f}(\mathrm{~mm})$ & $\theta^{\circ}$ & $a_{f}(\mathrm{~mm})$ & $b_{f}(\mathrm{~mm})$ & $\varnothing_{f}(\mathrm{~mm})$ & $E_{f}(\mathrm{GPa})$ & $f_{f}^{1}(\mathrm{kN})$ & $f_{f}^{2}(\mathrm{kN})$ & $f_{f}^{\exp }(\mathrm{kN})$ & $f_{f}^{1} / f_{f}^{\exp }$ & $f_{f}^{2} / f_{f}^{\exp }$ \\
\hline NB90-73-a-IV & 73 & 90 & - & - & 8.0 & 145.7 & 58.2 & 80.2 & 54.2 & 1.07 \\
NB90-73b-IV & 73 & 90 & - & - & 8.0 & 145.7 & 58.2 & 80.2 & 26.4 & 2.20 & 3.03 \\
NB90-45-b-IV & 45 & 90 & - & - & 8.0 & 145.7 & 73.76 & 130.0 & 28.6 & 2.57 & 4.54 \\
NB45-146-a-IV & 146 & 45 & - & - & 8.0 & 145.7 & 43.0 & 61.9 & 39.1 & 1.09 & 1.58 \\
NB45-73-a-IV & 73 & 45 & - & - & 8.0 & 145.7 & 49.6 & 120.7 & 28 & 1.77 & 4.31 \\
NS90-73-a-IV & 73 & 90 & 2 & 16 & & 121.5 & 48.9 & 49.8 & 50.5 & 0.96 & 0.98 \\
NS45-146-a-IV & 146 & 45 & 2 & 16 & & 121.5 & 38.7 & 40.1 & 32.7 & 1.18 & 1.22 \\
\hline
\end{tabular}


TABLE 5: Comparison between experimental results [112] and analytical results.

\begin{tabular}{lcccccccccc}
\hline Symbols & $S_{f}(\mathrm{~mm})$ & $\theta^{\circ}$ & $a_{f}(\mathrm{~mm})$ & $b_{f}(\mathrm{~mm})$ & $E_{f}(\mathrm{GPa})$ & $f_{f}^{1}(\mathrm{kN})$ & $f_{f}^{2}(\mathrm{kN})$ & $f_{f}^{\exp }(\mathrm{kN})$ & $f_{f}^{1} / f_{f}^{\exp }$ & $f_{f}^{2} / f_{f}^{\exp }$ \\
\hline VR-VII & 160 & 90 & 3.46 & 3.46 & 235 & 26.2 & 23.9 & 33.41 & 0.78 & 0.71 \\
IR-VII & 240 & 45 & 3.46 & 3.46 & 235 & 30.8 & 16.9 & 53.94 & 0.57 & 0.31 \\
VRA-VII & 160 & 90 & 3.46 & 3.46 & 235 & 26.2 & 23.9 & 39.88 & 0.65 \\
IRA-VII & 240 & 45 & 3.46 & 3.46 & 235 & 30.8 & 16.9 & 63.82 & 0.48 \\
VRA-VII & 160 & 90 & 3.46 & 3.46 & 235 & 26.2 & 23.9 & 29.4 & 0.59 \\
\hline
\end{tabular}

TABLE 6: Comparison between experimental results [90] and analytical results.

\begin{tabular}{|c|c|c|c|c|c|c|c|c|c|}
\hline Symbols & $S_{f}(\mathrm{~mm})$ & $\theta^{\circ}$ & $\varnothing_{f}(\mathrm{~mm})$ & $E_{f}(\mathrm{GPa})$ & $f_{f}^{1}(\mathrm{kN})$ & $f_{f}^{2}(\mathrm{kN})$ & $f_{f}^{\exp }(\mathrm{kN})$ & $f_{f}^{1} / f_{f}^{\exp }$ & $f_{f}^{2} / f_{f}^{\exp }$ \\
\hline B90-6a-VIII & 115 & 90 & 8.0 & 210 & 70.6 & 92.8 & 58.3 & 1.21 & 1.59 \\
\hline B90-6b-VIII & 115 & 90 & 8.0 & 124 & 67.4 & 92.8 & 55 & 1.22 & 1.68 \\
\hline B90-3a-VIII & 230 & 90 & 8.0 & 210 & 43.0 & 70.6 & 11 & 3.90 & 6.41 \\
\hline B90-3b-VIII & 230 & 90 & 8.0 & 124 & 45.6 & 70.6 & 6.3 & 7.23 & 11.20 \\
\hline B45-6a-VIII & 115 & 45 & 8.0 & 210 & 56.3 & 171.2 & 74.2 & 0.75 & 2.30 \\
\hline B45-6b-VIII & 115 & 45 & 8.0 & 124 & 66.1 & 171.2 & 98.2 & 0.67 & 1.74 \\
\hline B45-3a-VIII & 230 & 45 & 8.0 & 210 & 55.8 & 72.1 & 40.2 & 1.38 & 1.79 \\
\hline B45-3b-VIII & 230 & 45 & 8.0 & 124 & 48.1 & 72.1 & 81 & 0.59 & 0.89 \\
\hline S90-6a-VIII & 115 & 90 & 8.0 & 210 & 59.6 & 73.9 & 75.8 & 0.78 & 0.97 \\
\hline S90-6b-VIII & 115 & 90 & 8.0 & 124 & 56.9 & 73.9 & 38.9 & 1.46 & 1.89 \\
\hline S90-3a-VIII & 230 & 90 & 8.0 & 210 & 35.1 & 52.7 & 10.5 & 3.34 & 5.01 \\
\hline S90-3b-VIII & 230 & 90 & 8.0 & 124 & 37.2 & 52.7 & 20.4 & 1.82 & 2.58 \\
\hline S45-6a-VIII & 115 & 45 & 8.0 & 210 & 52.8 & 133.1 & 77.1 & 0.68 & 1.72 \\
\hline S45-6b-VIII & 115 & 45 & 8.0 & 124 & 62.0 & 133.1 & 106.4 & 0.58 & 1.25 \\
\hline S45-3a-VIII & 230 & 45 & 8.0 & 210 & 49.6 & 58.4 & 58.1 & 0.85 & 1.00 \\
\hline S45-3b-VIII & 230 & 45 & 8.0 & 124 & 42.8 & 58.4 & 98 & 0.43 & 0.59 \\
\hline
\end{tabular}

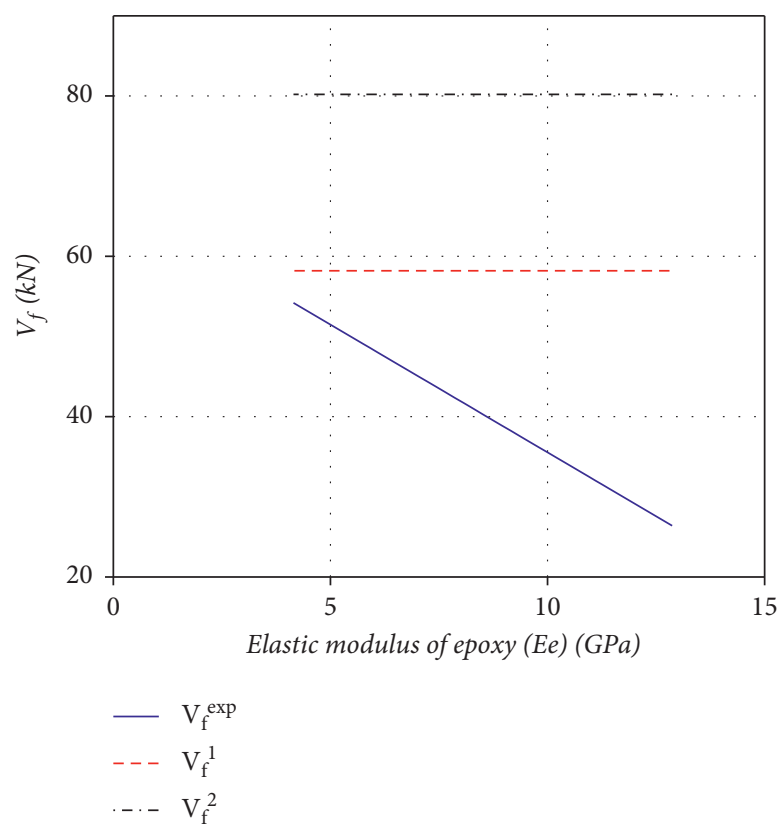

FIGURE 6: Effect of the elastic modulus of epoxy on the contribution of the NSM FRP shear strengthening technique (the experimental FRP contribution gained from [26]). 


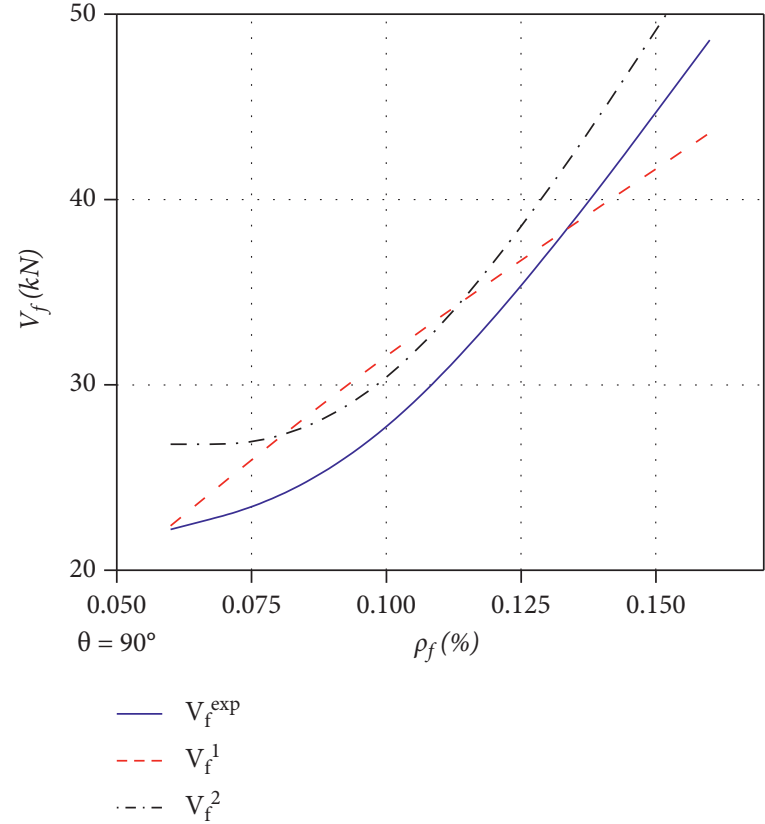

(a)

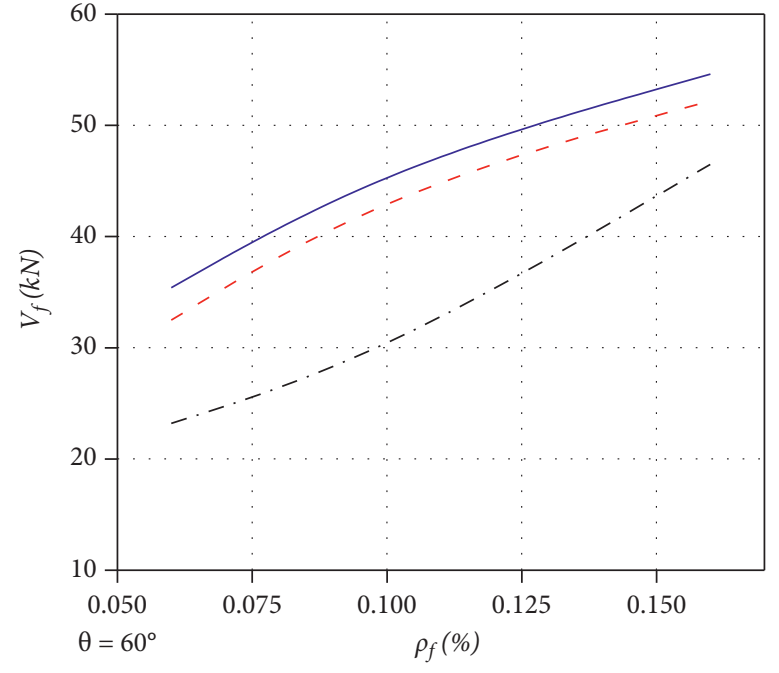

$-\mathrm{V}_{\mathrm{f}}^{\exp }$

$---V_{f}^{1}$

$\cdots V_{f}^{2}$

(b)

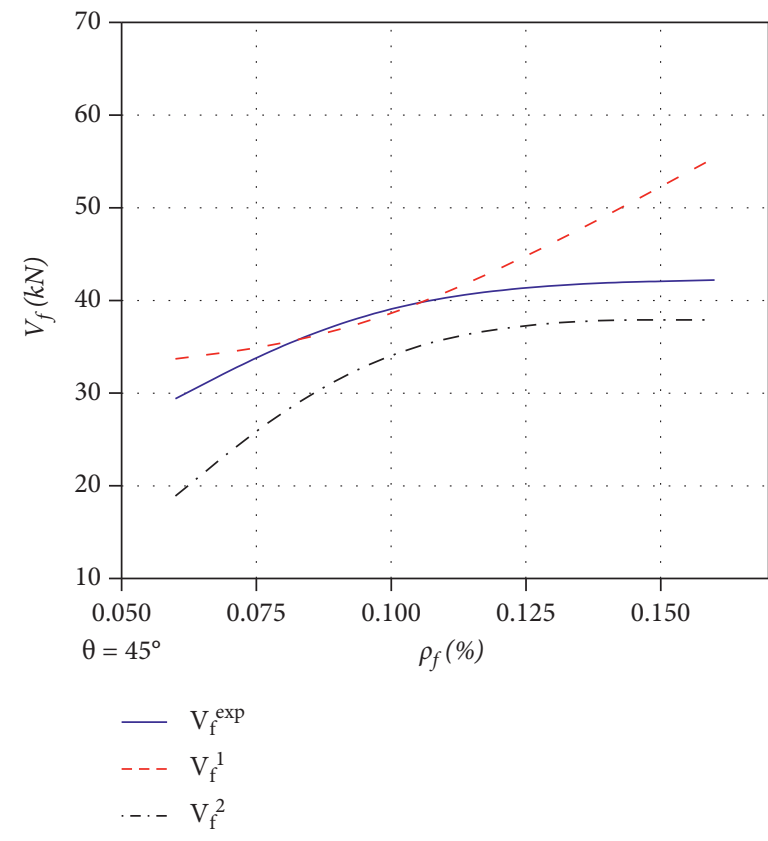

(c)

FIGURE 7: Effect of the percentage of the FRP for different reinforcement inclination angles on the contribution of the NSM FRP shear strengthening technique (the experimental FRP contribution gained from [27]).

while some of these were not investigated elsewhere such as the distance between existing shear reinforcement and SNM rods [113]. Generally, this powerful tool can more widely be used to investigate more parameters such as the percentage of steel stirrups against the percentage of NSM FRP rods and optimum distribution of FRP reinforcement along the beam. Numerical simulation is also needed to extend the parameter ranges outside those used in the experimental works. 


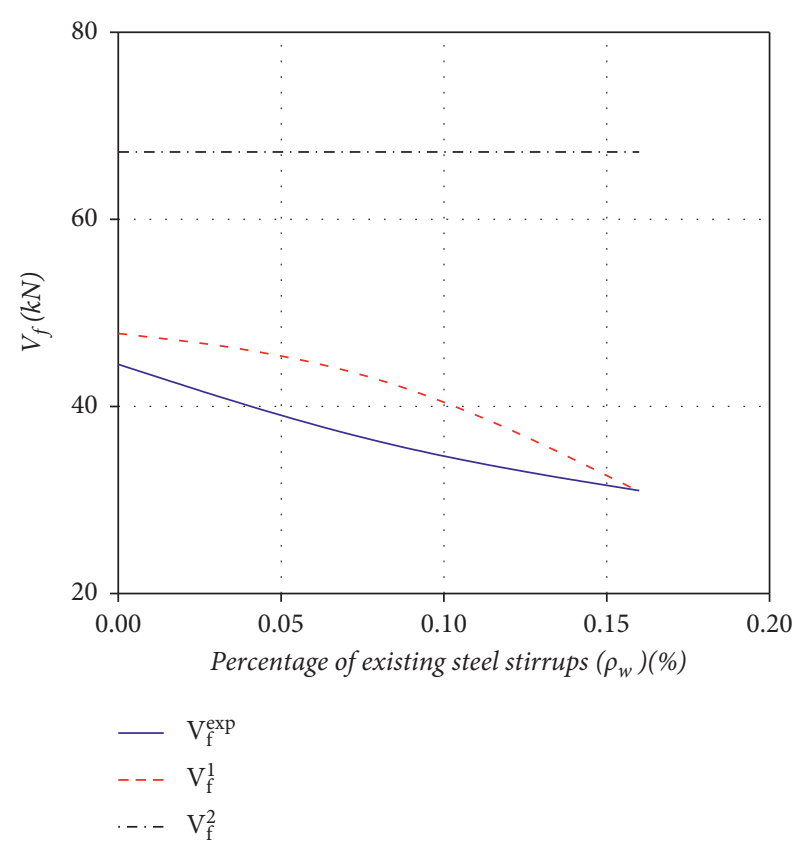

FIGURE 8: Effect of the percentage of existing steel stirrups on the contribution of the NSM FRP shear strengthening technique (the experimental FRP contribution gained from [27]).

\section{Conclusions}

This paper has provided a review of the current research on CFRP strengthened concrete beams with NSM technique in shear. Significant amounts of information and explanations of the existing researches on the NSM FRP strengthening of concrete beams have been provided. The important conclusions drawn from the reviewed studies can be summarized as follows:

(i) Although the bond between NSM FRP reinforcement and concrete substrate is well investigated, some debate is still ongoing on the selection of the real failure mode. Some researchers tend to present several failure modes because they look essential to the final appearance of the specimens, while others preferred to indicate only the conditioning failure mode.

(ii) Regarding the parameters that can influence the shear contribution of NSM FRP strengthening technique, it seems that most of these parameters are well covered. However, some of those still need deep investigation to remove the debate about that, such as the shape of NSM FRP reinforcement, inclination of NSM reinforcement, and percentage of the existing steel stirrups.

(iii) The most common failure mode of NSM FRP strengthened RC beams is the failure at the interface between NSM FRP reinforcement and adhesive layer, whereas the fracture of the concrete substrate surrounding groove is also commonly observed when normal or low concrete is used.

(iv) The study also considered a large number of experimental works to evaluate the contribution of
NSM strengthening in shear using formulations found in the literature. It appealed that the formula suggested by Dias and Barros [75] reasonably agrees with the experimental results with $9 \%$ of conservation.

\section{Conflicts of Interest}

The authors declare that they have no conflicts of interest.

\section{References}

[1] J. F. Chen and J. G. Teng, "Shear capacity of FRPstrengthened RC beams: FRP debonding," Construction and Building Materials, vol. 17, no. 1, pp. 27-41, 2003.

[2] C. P. Antonopoulos and T. C. Triantafillou, "Experimental investigation of FRP-strengthened RC beam-column joints," Journal of Composites for Construction, vol. 7, no. 1, pp. 39-49, 2003.

[3] L. C. Hollaway and J. G. Teng, Strengthening and Rehabilitation of Civil Infrastructures Using Fibre-Reinforced Polymer (FRP) Composites, Elsevier, Amsterdam, Netherlands, 2008.

[4] J. Bonacci and M. Maalej, "Behavioral trends of RC beams strengthened with externally bonded FRP," Journal of Composites for Construction, vol. 5, no. 2, pp. 102-113, 2001.

[5] J. Teng, L. Lam, and J. Chen, "Shear strengthening of RC beams with FRP composites," Progress in Structural Engineering and Materials, vol. 6, no. 3, pp. 173-184, 2004.

[6] M. M. A. Kadhim, "Effect of CFRP sheet length on the behavior of HSC continuous Beam," Journal of Thermoplastic Composite Materials, vol. 25, no. 1, pp. 33-44, 2012.

[7] M. M. A. Kadhim, M. J. Mohammed, and A. J. Chabuk, "Effect of prestressed CFRP plate location on behavior of RC beam strengthened with prestressed CFRP plate," Journal of the University of Bombay, vol. 20, no. 1, pp. 105-113, 2012.

[8] M. Badawi and K. Soudki, "Flexural strengthening of RC beams with prestressed NSM CFRP rods-experimental and analytical investigation," Construction and Building Materials, vol. 23, no. 10, pp. 3292-3300, 2009.

[9] A. Hajihashemi, D. Mostofinejad, and M. Azhari, "Investigation of RC beams strengthened with prestressed NSM CFRP laminates," Journal of Composites for Construction, vol. 15, no. 6, pp. 887-895, 2011.

[10] H. Y. Omran and R. E. Hacha, "Nonlinear 3D finite element modeling of RC beams strengthened with prestressed NSMCFRP strips," Construction and Building Materials, vol. 31, pp. 74-85, 2012.

[11] R. E. Hacha and S. H. Rizkalla, "Near-surface-mounted fiberreinforced polymer reinforcements for flexural strengthening of concrete structures," Structural Journal, vol. 101, no. 5, pp. 717-726, 2004.

[12] I. A. Sharaky, L. Torres, J. Comas, and C. Barris, "Flexural response of reinforced concrete (RC) beams strengthened with near surface mounted (NSM) fibre reinforced polymer (FRP) bars," Composite Structures, vol. 109, pp. 8-22, 2014.

[13] G. Sas, T. Blanksvärd, O. Enochsson, B. Täljsten, A. Puurula, and L. Elfgren, "Flexural-shear failure of a full scale tested RC bridge strengthened with NSM CFRP. Shear capacity analysis," Nordic Concrete Research, vol. 44, no. 13, pp. 189-204, 2011.

[14] B. Täljsten, J. Nilimaa, T. Blanksvärd, and G. Sas, "Flexuralshear failure of a full scale tested RC bridge strengthened with NSM CFRP," in Proceedings of the International 
Conference on Structural Health Monitoring of Intelligent Infrastructure, (SHMI), Cancún, México, December 2011.

[15] H. H. Kammona and A. S. H. A. Issawi, "Estimation of maximum shear capacity of RC deep beams strengthened by NSM steel bars," Journal of the University of Bombay, vol. 26, no. 3, pp. 13-22, 2018.

[16] S. J. Dias and J. A. Barros, "Performance of reinforced concrete $\mathrm{T}$ beams strengthened in shear with NSM CFRP laminates," Engineering Structures, vol. 32, no. 2, pp. 373-384, 2010.

[17] J. A. Barros, S. J. Dias, and J. L. Lima, "Efficacy of CFRPbased techniques for the flexural and shear strengthening of concrete beams," Cement and Concrete Composites, vol. 29, no. 3, pp. 203-217, 2007.

[18] M. R. Coelho, J. M. C. Sena, and L. A. Neves, "A review on the bond behavior of FRP NSM systems in concrete," Construction and Building Materials, vol. 93, pp. 1157-1169, 2015.

[19] P. Sabol and S. Priganc, "Shear strengthening of concrete members using NSM method," Procedia Engineering, vol. 65, pp. 364-369, 2013.

[20] A. A. M. Ali and T. M. Mezher, "Shear strengthening of RC without stirrups for deep beams with near surface mounted CFRP rods," International Journal of Engineering Research and Technology, vol. 4, no. 6, pp. 545-547, 2015.

[21] H. Tanarslan, "The effects of NSM CFRP reinforcements for improving the shear capacity of RC beams," Construction and Building Materials, vol. 25, no. 5, pp. 2663-2673, 2011.

[22] M. M. Kadhim, A. Jawdhari, and A. Peiris, "Evaluation of lap-splices in NSM FRP rods for retrofitting RC members," in StructuresElsevier, Amsterdam, Netherlands, 2021.

[23] S. S. Zhang, T. Yu, and G. Chen, "Reinforced concrete beams strengthened in flexure with near-surface mounted (NSM) CFRP strips: current status and research needs," Composites Part B: Engineering, vol. 131, pp. 30-42, 2017.

[24] N. T. K. A. Saadi, A. Mohammed, R. A. Mahaidi, and J. Sanjayan, "Performance of NSM FRP embedded in concrete under monotonic and fatigue loads: state-of-the-art review," Australian Journal of Structural Engineering, vol. 20, no. 2, pp. 89-114, 2019.

[25] L. D. Lorenzis and J. Teng, "Near-surface mounted FRP reinforcement: an emerging technique for strengthening structures," Composites Part B: Engineering, vol. 38, no. 2, pp. 119-143, 2007.

[26] A. Rizzo and L. D. Lorenzis, "Behavior and capacity of RC beams strengthened in shear with NSM FRP reinforcement," Construction and Building Materials, vol. 23, no. 4, pp. 1555-1567, 2009.

[27] S. J. Dias and J. A. Barros, "Shear strengthening of T cross section reinforced concrete beams by near-surface mounted technique," Journal of Composites for Construction, vol. 12, no. 3, pp. 300-311, 2008.

[28] S. J. Dias and J. A. Barros, "NSM shear strengthening technique with CFRP laminates applied in high $\mathrm{T}$ cross section RC beams," Composites Part B: Engineering, vol. 114, pp. 256-267, 2017.

[29] S. Dias and J. Barros, "NSM shear strengthening technique with CFRP laminates applied in high-strength concrete beams with or without pre-cracking," Composites Part B: Engineering, vol. 43, no. 2, pp. 290-301, 2012.

[30] A. Mofidi, O. Chaallal, L. Cheng, and Y. Shao, "Investigation of near surface-mounted method for shear rehabilitation of reinforced concrete beams using fiber reinforced-polymer composites," Journal of Composites for Construction, vol. 20, no. 2, Article ID 04015048, 2015.
[31] B. Almassri, A. Kreit, F. A. Mahmoud, and R. Francois, "Behaviour of corroded shear-critical reinforced concrete beams repaired with NSM CFRP rods," Composite Structures, vol. 123, pp. 204-215, 2015.

[32] R. Seracino, N. M. Jones, M. Ali, M. W. Page, and D. J. Oehlers, "Bond strength of near-surface mounted FRP strip-to-concrete joints," Journal of Composites for Construction, vol. 11, no. 4, pp. 401-409, 2007.

[33] D. Lee, L. Cheng, and J. Y. G. Hui, "Bond characteristics of various NSM FRP reinforcements in concrete," Journal of Composites for Construction, vol. 17, no. 1, pp. 117-129, 2012.

[34] A. Bilotta, F. Ceroni, E. Nigro, and M. Pecce, "Strain assessment for the design of NSM FRP systems for the strengthening of RC members," Construction and Building Materials, vol. 69, pp. 143-158, 2014.

[35] W. Perera, T. Ibell, and A. Darby, "Bond behaviour and effectiveness of various shapes of NSM CFRP bars," in Proceedings of the 9th Int. Symp. on Fiber-Reinforced Polymers Reinforcement for Concrete Structures (FRPRCS-9), pp. 250-258, Edinburgh, Scotland, tember 2009.

[36] W. Kalupahana, T. Ibell, and A. Darby, "Bond characteristics of near surface mounted CFRP bars," Construction and Building Materials, vol. 43, pp. 58-68, 2013.

[37] J. A. Barros, S. J. Dias, H. Baghi, and A. V. Gouveia, "New shear strengthening configurations of near-surface-mounted CFRP laminates for RC beams," Structural Journal, vol. 113, no. 6, pp. 1275-1287, 2016.

[38] S. J. Dias and J. A. Barros, "Experimental research of a new CFRP-based shear strengthening technique for reinforced concrete beams," IBRACON Structural Journal, 2005.

[39] T. G. Wakjira and U. Ebead, "Hybrid NSE/EB technique for shear strengthening of reinforced concrete beams using FRCM: experimental study," Construction and Building Materials, vol. 164, pp. 164-177, 2018.

[40] L. D. Lorenzis, A. Rizzo, and A. L. Tegola, "A modified pullout test for bond of near-surface mounted FRP rods in concrete," Composites Part B: Engineering, vol. 33, no. 8, pp. 589-603, 2002.

[41] J. Teng, L. D. Lorenzis, B. Wang, R. Li, T. Wong, and L. Lam, "Debonding failures of RC beams strengthened with near surface mounted CFRP strips," Journal of Composites for Construction, vol. 10, no. 2, pp. 92-105, 2006.

[42] S. E. Gamal, Y. A. Salloum, S. Alsayed, and M. Aqel, "Performance of near surface mounted glass fiber reinforced polymer bars in concrete," Journal of Reinforced Plastics and Composites, vol. 31, no. 22, pp. 1501-1515, 2012.

[43] F. A. Mahmoud, A. Castel, T. Q. Minh, and R. François, "Reinforced concrete beams strengthened with NSM CFRP rods in shear," Advances in Structural Engineering, vol. 18, no. 10, pp. 1563-1574, 2015.

[44] T. Hassan and S. Rizkalla, "Bond mechanism of NSM FRP bars for flexural strengthening of concrete structures," ACI Structural Journal, vol. 101, no. 6, pp. 830-839, 2004.

[45] A. Bilotta, F. Ceroni, M. D. Ludovico, E. Nigro, M. Pecce, and G. Manfredi, "Bond efficiency of EBR and NSM FRP systems for strengthening concrete members," Journal of Composites for Construction, vol. 15, no. 5, pp. 757-772, 2011.

[46] F. Ceroni, M. Pecce, A. Bilotta, and E. Nigro, "Bond behavior of FRP NSM systems in concrete elements," Composites Part B: Engineering, vol. 43, no. 2, pp. 99-109, 2012.

[47] I. A. Sharaky, L. Torres, M. Baena, and C. Miàs, "An experimental study of different factors affecting the bond of NSM FRP bars in concrete," Composite Structures, vol. 99, pp. 350-365, 2013. 
[48] I. A. Sharaky, L. Torres, M. Baena, and I. Vilanova, "Effect of different material and construction details on the bond behaviour of NSM FRP bars in concrete," Construction and Building Materials, vol. 38, pp. 890-902, 2013.

[49] D. Oehlers, R. Rashid, and R. Seracino, "IC debonding resistance of groups of FRP NSM strips in reinforced concrete beams," Construction and Building Materials, vol. 22, no. 7, pp. 1574-1582, 2008.

[50] D. Galati and L. De Lorenzis, "Effect of construction details on the bond performance of NSM FRP bars in concrete," Advances in Structural Engineering, vol. 12, no. 5, pp. 683700, 2009.

[51] P. M. Fernandes, P. M. Silva, and J. C. Sena, "Bond and flexural behavior of concrete elements strengthened with NSM CFRP laminate strips under fatigue loading," Engineering Structures, vol. 84, pp. 350-361, 2015.

[52] N. Wahab, K. A. Soudki, and T. Topper, "Experimental investigation of bond fatigue behavior of concrete beams strengthened with NSM prestressed CFRP rods," Journal of Composites for Construction, vol. 16, no. 6, pp. 684-692, 2012.

[53] A. S. Kalayci, B. Yalim, and A. Mirmiran, "Construction tolerances and design parameters for NSM FRP reinforcement in concrete beams," Construction and Building $\mathrm{Ma}$ terials, vol. 24, no. 10, pp. 1821-1829, 2010.

[54] R. Rashid, D. Oehlers, and R. Seracino, "IC debonding of FRP NSM and EB retrofitted concrete: plate and cover interaction tests," Journal of Composites for Construction, vol. 12, no. 2, pp. 160-167, 2008.

[55] C. Shield, C. French, and E. Milde, The Effect of Adhesive Type on the Bond of NSM Tape to Concrete, vol. 230, pp. 355-372, Special Publication, American Concrete Institute, Kansas, MO, USA, 2005.

[56] N. Wahab, K. A. Soudki, and T. Topper, "Mechanics of bond fatigue behavior of concrete beams strengthened with NSM CFRP rods," Journal of Composites for Construction, vol. 15, no. 6, pp. 934-942, 2011.

[57] M. M. Ali, D. Oehlers, M. Griffith, and R. Seracino, "Interfacial stress transfer of near surface-mounted FRP-toconcrete joints," Engineering Structures, vol. 30, no. 7, pp. 1861-1868, 2008.

[58] A. Bilotta, F. Ceroni, J. A. Barros et al., "Bond of NSM FRPstrengthened concrete: round robin test initiative," Journal of Composites for Construction, vol. 20, no. 1, Article ID 04015026, 2015.

[59] D. Lee and L. Cheng, "Bond of NSM systems in concrete strengthening-examining design issues of strength, groove detailing and bond-dependent coefficient," Construction and Building Materials, vol. 47, pp. 1512-1522, 2013.

[60] J. R. Garzón, J. M. C. Sena, P. Fernandes, and J. Xavier, "Effect of wet-dry cycles on the bond behaviour of concrete elements strengthened with NSM CFRP laminate strips," Composite Structures, vol. 132, pp. 331-340, 2015.

[61] K. Borchert and K. Zilch, "Bond behaviour of NSM FRP strips in service," Structural Concrete, vol. 9, no. 3, pp. 127-142, 2008.

[62] I. Costa and J. A. Barros, "Assessment of the bond behaviour of NSM FRP materials by pullout tests," in Proceedings of the in First Middle East Conference on Smart Monitoring, Assessment and Rehabilitation of Civil Structures (SMAR 2011), 2011. International Society for Structural Health Monitoring of Intelligent, Dubai, UAE, February 2011.

[63] L. Lorenzis and A. Nanni, "Bond between near-surface mounted fiber-reinforced polymer rods and concrete in structural strengthening," Structural Journal, vol. 99, no. 2, pp. 123-132, 2002.

[64] S. M. Soliman, E. E. Salakawy, and B. Benmokrane, "Bond performance of near-surface-mounted FRP bars," Journal of Composites for Construction, vol. 15, no. 1, pp. 103-111, 2010.

[65] J. M. C. Sena, J. A. Barros, R. Gettu, and A. F. Azevedo, "Bond behavior of near-surface mounted CFRP laminate strips under monotonic and cyclic loading," Journal of Composites for Construction, vol. 10, no. 4, pp. 295-303, 2006.

[66] X. Yan, B. Miller, A. Nanni, and C. Bakis, "Characterization of CFRP rods used as near surface mounted reinforcement," in Proceedings of the 8th International conference on structural faults and repair, Edinburgh, Scotland, July 1999.

[67] J. A. Barros and J. C. Sena, "Bond behavior of carbon laminate strips into concrete by pullout-bending tests," in Proceedings of the third International Symposium on Bond in Concrete, Budapest, Hungary, November 2002.

[68] A. A. Abdwais and R. A. Mahaidi, "Modified cement-based adhesive for near-surface mounted CFRP strengthening system," Construction and Building Materials, vol. 124, pp. 794-800, 2016.

[69] J. M. D. C. Sena and J. A. D. B. Oliveira, "Bond between nearsurface mounted carbon-fiber-reinforced polymer laminate strips and concrete," Journal of Composites for Construction, vol. 8, no. 6, pp. 519-527, 2004.

[70] D. Novidis, S. J. Pantazopoulou, and E. Tentolouris, "Experimental study of bond of NSM-FRP reinforcement," Construction and Building Materials, vol. 21, no. 8, pp. 1760-1770, 2007.

[71] I. Sharaky, R. Reda, M. Ghanem, M. Seleem, and H. Sallam, "Experimental and numerical study of RC beams strengthened with bottom and side NSM GFRP bars having different end conditions," Construction and Building Materials, vol. 149, pp. 882-903, 2017.

[72] K. Nasrollahzadeh and S. Afzali, "Fuzzy logic model for pullout capacity of near-surface-mounted FRP reinforcement bonded to concrete," Neural Computing \& Applications, vol. 31, no. 11, pp. 7837-7865, 2019.

[73] M. Mirrashid and H. Naderpour, "Recent trends in prediction of concrete elements behavior using soft computing (2010-2020)," Archives of Computational Methods in Engineering, vol. 28, no. 4, pp. 3307-3327, 2021.

[74] S. Dias and J. Barros, "Shear strengthening of RC T-section beams with low strength concrete using NSM CFRP laminates," Cement and Concrete Composites, vol. 33, no. 2, pp. 334-345, 2011.

[75] S. J. Dias and J. A. Barros, "Shear strengthening of RC beams with NSM CFRP laminates: experimental research and analytical formulation," Composite Structures, vol. 99, pp. 477-490, 2013.

[76] H. E. Emam, A. E. Sisi, M. Bneni, S. S. Ahmad, and H. E. D. M. Sallam, "Effects of tensile reinforcing steel ratio and Near-Surface-Mounted bar development length on the structural behavior of strengthened RC beams," Latin American Journal of Solids and Structures, vol. 17, 2020.

[77] I. Sharaky, M. Baena, C. Barris, H. Sallam, and L. Torres, "Effect of axial stiffness of NSM FRP reinforcement and concrete cover confinement on flexural behaviour of strengthened RC beams: experimental and numerical study," Engineering Structures, vol. 173, pp. 987-1001, 2018.

[78] R. M. Reda, Z. Omar, H. Sallam, and S. S. Ahmad, "Effect of different parameters controlling the flexural behavior of RC beams strengthened with NSM using nonlinear finite 
element analysis," Frattura Ed Integrità Strutturale, vol. 14, no. 53, pp. 106-123, 2020.

[79] L. D. Lorenzis and A. Nanni, "Shear strengthening of reinforced concrete beams with near-surface mounted fiberreinforced polymer rods," ACI Structural Journal, vol. 98, no. 1, pp. 60-68, 2001.

[80] S. J. Dias and J. A. Barros, "Experimental behaviour of RC beams shear strengthened with NSM CFRP laminates," Strain, vol. 48, no. 1, pp. 88-100, 2012.

[81] D. Cisneros, A. Arteaga, A. D. Diego, A. Alzate, and R. Perera, "Experimental study on NSM FRP shear retrofitting of RC beams," in Proceedings of the Sixth International Conference on FRP Composites in Civil Engineering (CICE2012), Rome, Italy, June 2012.

[82] T. E. Maaddawy and Y. Chekfeh, "Shear strengthening of t-beams with corroded stirrups using composites," ACI Structural Journal, vol. 110, no. 5, p. 779, 2013.

[83] H. E. M. Abou, A. Sherbini, and H. Sallam, "Structural behavior of RC beams containing a pre-diagonal tension crack," Latin American Journal of Solids and Structures, vol. 15, 2018.

[84] H. E. M. Abou, A. Sherbini, and H. Sallam, "Locating the site of diagonal tension crack initiation and path in reinforced concrete beams," Ain Shams Engineering Journal, vol. 6, no. 1, pp. 17-24, 2015.

[85] H. E. M. Abou, A. Sherbini, and H. Sallam, "Mode II fracture toughness of hybrid FRCs," International Journal of Concrete Structures and Materials, vol. 9, no. 4, pp. 475-486, 2015.

[86] H. E. Sallam and K. Fawzy, "Stirrups in RC beams: facts beyond assumptions," in Proceedings of the 5th ICCAE Conf, ICCAE, Cairo, Egypt, November 2004.

[87] I. A. Sharaky, L. Torres, and H. Sallam, "Experimental and analytical investigation into the flexural performance of RC beams with partially and fully bonded NSM FRP bars/strips," Composite Structures, vol. 122, pp. 113-126, 2015.

[88] J. A. Barros and S. J. Dias, "Near surface mounted CFRP laminates for shear strengthening of concrete beams," Cement and Concrete Composites, vol. 28, no. 3, pp. 276-292, 2006.

[89] Y. S. A. Rjoub, A. M. Ashteyat, Y. T. Obaidat, and S. Y. Bani, "Shear strengthening of RC beams using near-surface mounted carbon fibre-reinforced polymers," Australian Journal of Structural Engineering, vol. 20, no. 1, pp. 54-62, 2019.

[90] K. N. Rahal and H. A. Rumaih, “Tests on reinforced concrete beams strengthened in shear using near surface mounted CFRP and steel bars," Engineering Structures, vol. 33, no. 1, pp. 53-62, 2011.

[91] D. Lim, "Shear behaviour of RC beams strengthened with NSM and EB CFRP strips," Magazine of Concrete Research, vol. 62, no. 3, pp. 211-220, 2010.

[92] S. J. Dias and J. A. Barros, "NSM CFRP laminates for the shear strengthening of T section RC beams," Iinternational FIB Congress, vol. 2, 2006.

[93] R. Reda, I. Sharaky, M. Ghanem, M. Seleem, and H. Sallam, "Flexural behavior of RC beams strengthened by NSM GFRP Bars having different end conditions," Composite Structures, vol. 147, pp. 131-142, 2016.

[94] H. E.-D. M. Sallam, A.-A. M. Saba, H. H. Shahin, and H. R. Abdel, "Prevention of peeling failure in plated beams," Journal of Advanced Concrete Technology, vol. 2, no. 3, pp. 419-429, 2004.

[95] K. Fawzy and H. Sallam, "Shear strengthening of rc beams by near surface mounted (nsm) steel strips," in Proceedings of the 11th International Colloquium on Structural and Geotechnical Engineering, Cairo, Egypt, May 2005.

[96] S. A. Bellamkonda, Modeling of Shear Strengthening of Reinforced concrete Beams Retrofitted with Externally Bonded Fiber Reinforced Polymers, Master Thesis, Louisiana State University, LA, USA, 2013.

[97] V. Bianco, G. Monti, and J. A. Barros, "Design formula to evaluate the NSM FRP strips shear strength contribution to a RC beam," Composites Part B: Engineering, vol. 56, pp. 960-971, 2014.

[98] A. Nanni, M. D. Ludovico, and R. Parretti, "Shear strengthening of a PC bridge girder with NSM CFRP rectangular bars," Advances in Structural Engineering, vol. 7, no. 4, pp. 297-309, 2004.

[99] H. Baghi and J. A. Barros, "Design approach to determine shear capacity of reinforced concrete beams shear strengthened with NSM systems," Journal of Structural Engineering, vol. 143, no. 8, Article ID 04017061, 2017.

[100] V. Bianco, G. Monti, and J. A. Barros, "Theoretical model and computational procedure to evaluate the NSM FRP strips shear strength contribution to a RC beam," Journal of Structural Engineering, vol. 137, no. 11, pp. 1359-1372, 2010.

[101] V. Bianco, J. A. Barros, and G. Monti, "Influence of the concrete mechanical properties on the efficacy of the shear strengthening intervention on rc beams by nsm technique," in Proceedings of the Asia-Pacific Conference on FRP in Structures (APFIS 2007), Hong Kong, China, December 2007.

[102] H. Baghi and J. A. Barros, "New approach to predict shear capacity of reinforced concrete beams strengthened with NSM technique," Structural Journal, vol. 1, no. 114, pp. 137-148, 2017.

[103] J. A. Barros, V. Bianco, and G. Monti, "NSM CFRP laminates for shear strengthening of RC beams: tests and mechanical model," The Open Construction \& Building Technology Journal, vol. 3, pp. 12-32, 2009.

[104] D. M. Prado, I. D. G. Araujo, V. G. Haach, and R. Carrazedo, "Assessment of shear damaged and NSM CFRP retrofitted reinforced concrete beams based on modal analysis," Engineering Structures, vol. 129, pp. 54-66, 2016.

[105] V. Bianco, J. A. Barros, and G. Monti, "New approach for modeling the contribution of NSM FRP strips for shear strengthening of RC beams," Journal of Composites for Construction, vol. 14, no. 1, pp. 36-48, 2010.

[106] V. Bianco, J. A. Barros, and G. Monti, "Three dimensional mechanical model for simulating the NSM FRP strips shear strength contribution to RC beams," Engineering Structures, vol. 31, no. 4, pp. 815-826, 2009.

[107] A. Rizzo and L. D. Lorenzis, "Modeling of debonding failure for RC beams strengthened in shear with NSM FRP reinforcement," Construction and Building Materials, vol. 23, no. 4, pp. 1568-1577, 2009.

[108] V. Bianco, J. A. Barros, and G. Monti, "A new approach for modelling the nsm shear strengthening contribution in reinforced concrete beams," in Proceedings of the Fiber Reinforced Polymer for Reinforced Concrete Structures, Patras, Greece, July 2007.

[109] ACI-318-14, "Building code requirements for reinforced concrete," 2014.

[110] ACI-440-Committee, Guide for the Design and Construction of Externally Bonded FRP Systems for Strengthening concrete Structures. ACI-440.2 R-08, American Concrete Institute, Farmington Hills, MI, USA, 2008. 
[111] A. A. Islam, "Effective methods of using CFRP bars in shear strengthening of concrete girders," Engineering Structures, vol. 31, no. 3, pp. 709-714, 2009.

[112] M. Jalali, M. K. Sharbatdar, J. F. Chen, and F. J. Alaee, "Shear strengthening of RC beams using innovative manually made NSM FRP bars," Construction and Building Materials, vol. 36, pp. 990-1000, 2012.

[113] M. M. Kadhim, A. H. Adheem, and A. R. Jawdhari, "Nonlinear finite element modelling and parametric analysis of shear strengthening RC T-beams with NSM CFRP technique," International Journal of Civil Engineering, vol. 17, pp. 1-12, 2019.

[114] V. Bianco, J. A. Barros, and G. Monti, "Three dimensional mechanical model to simulate the NSM FRP strips shear strength contribution to a RC beam: parametric studies," Engineering Structures, vol. 37, pp. 50-62, 2012.

[115] J. A. Barros, H. Baghi, S. J. Dias, and A. G. Ventura, “A FEMbased model to predict the behaviour of RC beams shear strengthened according to the NSM technique," Engineering Structures, vol. 56, pp. 1192-1206, 2013. 